\title{
Survey on salt content in selected food products of fast food restaurants and determination of salt intake awareness among fast food consumers in Klang Valley
}

\author{
Zainorain Natasha Zainal Arifen ${ }^{1}$, Nur Zakiah Mohd Saat ${ }^{2} \&$ Hasnah \\ Haron $^{1^{*}}$
}

${ }^{1}$ Nutritional Sciences Programme and Centre for Healthy Ageing and Wellness, Faculty of Health Sciences, Universiti Kebangsaan Malaysia, Kuala Lumpur, Malaysia; ${ }^{2}$ Programme of Biomedical Science, School of Community Studies (ReaCH), Faculty of Health Sciences, Universiti Kebangsaan Malaysia, Kuala Lumpur, Malaysia

\begin{abstract}
Introduction: Malaysians are exposed to a high salt diet, which is one of the contributors to the prevalence of hypertension among them. This study aimed to identify the salt content in selected food products of fast food restaurants and to determine the salt intake awareness among fast food consumers. Methods: Salt content data were collected through online survey from the official websites of selected restaurants (Kentucky Fried Chicken, McDonald's, Subway ${ }^{\circledR}$ and Texas Chicken). The food products were classified into eight food categories (chickenbased, potato-based, rice-based, sandwich, salad, bread, dessert, and sauce). The cross-sectional study on salt intake awareness was conducted among 108 Malaysian adults from these restaurants. A knowledge, attitude and practice (KAP) questionnaire was disseminated online. The salt content and the consumers' salt intake awareness were analysed using Statistical Products and Service Solution (SPSS) software version 25.0. Results: A total of 105 food products were surveyed in this study. Sauce products contained the highest salt content $(1.9 \pm 0.8 \mathrm{~g} / 100 \mathrm{~g})$, followed by bread $(1.2 \pm 0.3 \mathrm{~g} / 100 \mathrm{~g})$, potato-based $(1.2 \pm 0.4 \mathrm{~g} / 100 \mathrm{~g})$, chicken-based $(1.2 \pm 0.3 \mathrm{~g} / 100 \mathrm{~g})$, sandwich $(1.1 \pm 0.6 \mathrm{~g} / 100 \mathrm{~g})$, rice-based $(0.7 \pm 0.3 \mathrm{~g} / 100 \mathrm{~g})$, salad $(0.4 \pm 0.2 \mathrm{~g} / 100 \mathrm{~g})$, and dessert $(0.3 \pm 0.4 \mathrm{~g} / 100 \mathrm{~g})$. For the KAP study, a total of 108 consumers had participated and mostly $(48.2 \%)$ had a fair level of salt intake awareness. Conclusion: Most food products of fast food restaurants contained high salt content and majority of fast food consumers had a fair level of salt intake awareness. More strategic interventions are needed to control the salt intake among adults in Malaysia.
\end{abstract}

Keywords: salt, sodium chloride, fast foods, awareness

\section{INTRODUCTION}

The fifth National Health and Morbidity Survey (NHMS) by the Institute for Public Health (IPH, 2015) reported that the prevalence of hypertension in Malaysia is currently at $30.3 \%$ for adults aged 18 years and above. In addition, Malaysia's latest Burden of Disease Study (IPH,

\footnotetext{
*Corresponding author: Assoc. Prof. Dr Hasnah Haron

Nutritional Sciences Programme and Centre for Healthy Ageing and Wellness (HCare)

Faculty of Health Sciences, Universiti Kebangsaan Malaysia, Kuala Lumpur, Malaysia

Tel: (6)(03)92897457; Fax: (6)(03)26947621; E-mail: hasnaharon@ukm.edu.my

doi: https://doi.org/10.31246/mjn-2020-0120
} 
2017) revealed that hypertension is estimated to cause $42.2 \%$ of deaths and $21.6 \%$ of disease burden (DALY) among both men and women. High or excess salt intake are stated to be one of the factors for hypertension (Mozaffarian et al., 2014). In the 2020 Malaysian Dietary Guidelines (MDG), hypertension is said to be one of the main risk factors for developing cardiovascular diseases and premature death (NCCFN, 2021).

According to the tenth key message of MDG (NCCFN, 2021), that is "choose and prepare food with less salt, sauces and flavour enhancers", a way to limit salt intake to $5 \mathrm{~g} /$ day is to reduce the consumption of fast foods. In the nutrition area, fast food is defined as "processed food that needs a minimum and quick preparation before consumption" or "food that is prepared quickly in fast food restaurants" (Dewan Bahasa dan Pustaka, 2010). MySalt 2015 study (IPH, 2016) also stated that fast food is a high salt food. Moreover, the Malaysian Adult Nutrition Survey (MANS) 2014 (IPH, 2014) had also added fast foods consisting of burgers, pizzas, potatoes, sausages, nuggets, coleslaw, fried chicken, and mashed potatoes as a new category compared to MANS 2003. Since fast food restaurants can be found nearly everywhere nowadays and is convenient since the food takes less time to prepare, phase one of this study aimed to survey the salt and sodium content in selected food products of fast food restaurants available in Klang Valley. The salt and sodium content of these food products were also compared between categories and to the respective sodium criteria stated in the International Product Criteria (IPC) (Choices International Foundation, 2016).

A study by Ambak et al. (2014) using 24-hour urine analysis reported that the average intake of salt even among normotensive health staffs of the Ministry of Health (MOH) Malaysia was $8.7 \mathrm{~g} /$ day, which exceeded the $5 \mathrm{~g}$ of salt per day as recommended by the World Health Organization (WHO, 2012). This is especially concerning, since salt intake among a population working in the health sector was expected to be below average. Therefore, the second phase of this study was to determine the knowledge $(\mathrm{K})$, attitude $(\mathrm{A})$ and practice (P), as well as the overall awareness (KAP) on salt intake among the Malaysian population, which was expected to be better than the population studied by Ambak et al. (2014).

This study is important as the findings may assist Malaysia's $\mathrm{MOH}$ in their aim to reduce salt intake by $30 \%$ and the prevalence of hypertension by $25 \%$ among adults in Malaysia by the year 2025 (MOH, 2016). Additionally, salt intake reduction is the easiest and most cost-effective way to reduce the prevalence of hypertension $(\mathrm{MOH}, 2016)$.

\section{MATERIALS AND METHODS}

\section{Study design}

The current study comprised of two phases. The first phase of the study consisted of an online survey on fast foods and their nutrition information available in purposively selected fast food restaurants. The second phase was a cross-sectional study to determine the awareness of salt intake among the Malaysian population.

\section{Food samples}

The restaurants involved in the study were Kentucky Fried Chicken (KFC), McDonald's, Subway ${ }^{\circledR}$, and Texas Chicken, which were purposively selected for this study. For KFC and McDonald's, an online surveying of the menus available in the restaurants was conducted through the restaurants' Malaysia official websites; whereas for Subway ${ }^{\circledR}$ and Texas Chicken, data consisting of the menus available with 
the respective nutrition information were obtained by personally emailing the respective department of the restaurants, as data given were solely intended for this research study and not available to the public. The list of food products available on the restaurants' menus were then grouped into these respective categories: chicken-based (chicken nuggets, fried chicken, chicken tenders); potato-based (french fries, mashed potatoes, hash browns, potato wedges); rice-based (rice congee, nasi lemak, cooked rice); sandwich (wraps, burgers); salad, bread, dessert (cakes, ice creams, pies, biscuits, sweet corn), and sauce products. These categories were identified following reports from O'Donnell et al. (2018) and Dunford et al. (2012). The data collected consisted of:

(a) Product name

(b) Serving size (g)

(c) Salt content (g) in every serving and every $100 \mathrm{~g}$ serving

(d) Sodium content (mg) in every serving and every $100 \mathrm{~g}$ serving

If only the salt content was available, sodium content of the product was obtained by multiplying the salt content with 400 since $5 \mathrm{~g}$ of salt contains 2000 mg of sodium (WHO, 2012). Following the identification of the salt and sodium content, the sodium content for each product was compared to the sodium content in the IPC by Choices International Foundation (2016), and the percentage of products that exceeded the criteria was determined. The average salt and sodium content for every category was then calculated and compared between categories and to their own criteria.

\section{Subjects}

This cross-sectional study was conducted online among Malaysian adults who gave their informed consent to participate.
Malaysian adults who were eligible for this study were those who had experienced eating food products from KFC, McDonald's, Subway ${ }^{\circledR}$, and Texas Chicken in the Klang Valley area. The potential subjects were selected using convenience sampling, in which they were approached through WhatsApp, Instagram or Twitter. Those who were not Malaysians, below 18 years old or did not have any experiences eating food products from the selected restaurants were excluded. Subjects were provided with a KAP questionnaire on salt intake that consisted of an informed consent, information sheet of the study, and the questionnaire itself if they abided by the accepted criteria.

The sample size was calculated according to Cochran (1977), $n=\left[\left(z_{\mathrm{a} / 2}\right)^{2}\right.$ $p(1-p)] / \Delta^{2}$, in which $n$ indicates the desired sample, $z_{\mathrm{a} / 2}$ indicates the critical value at significant value of $0.10 \%, p$ indicates the population of subject that practices salt intake control according to the MySalt 2015 study (IPH, 2016), and $\Delta$ indicates the level of accuracy. Assuming $90 \%$ confidence level, $z_{\mathrm{a} / 2}$ of $1.645, p$ of 0.613 , and $\Delta$ of 0.10 , the sample size was calculated as $n=\left[(1.645)^{2}\right.$ $0.613(1-0.613)] / 0.10^{2}$. According to this formula and after assuming that the drop-out rate of subjects was $20 \%$, the needed sample size was 77 . However, a total of 108 subjects had participated in this study.

Prior to the start of the study, ethical approval was provided by the Research Ethics Committee of Universiti Kebangsaan Malaysia with reference number UKM.FSK.800-1/1/5 (NN2019-133).

\section{KAP questionnaire}

KAP towards salt intake was assessed using a validated questionnaire that was administered through Google Forms. The KAP questionnaire on salt intake was retrieved from the MySalt 2015 study 
(IPH, 2016), which had adapted the questionnaire from $\mathrm{WHO}$ and validated it. In the current study, the MySalt 2015 study (IPH, 2016) questionnaire was modified and validated again. The questionnaire consisted of an informed consent, information sheet, and the questionnaire itself. The subjects needed to fulfil every acceptable criteria of participation, and every question must be answered before proceeding to the next question. Another four questions regarding knowledge, five questions regarding attitude, and one question regarding practice towards salt intake were added in this study. Validation was performed by pre-testing the modified set of questionnaires on 65 Malaysian adults who had experience eating food products from the selected restaurants in Klang Valley. The reliability was then analysed using Cronbach's alpha analysis. Cronbach's alpha for KAP was 0.70 indicating that the reliability for the KAP scores were good (Cronbach's alpha $\geq 0.07$ ) (Pallant, 2005).

The knowledge, attitude and practice domains comprised of six questions each with multiple choice answers. Different marks were given for each answer, and the scores for every domain and KAP were presented as mean \pm standard deviation $(S D)$ in percentages. For the knowledge domain, subjects who scored $<60 \%$ were categorised as having poor level, 60$70 \%$ as fair, and $>70 \%$ as good. For the attitude domain, subjects who scored $<60 \%$ were categorised as negative, 60$70 \%$ as neutral, and $>70 \%$ as positive. Meanwhile, for practice domain, subjects who scored $<60 \%$ were categorised as inadequate, $60-70 \%$ as adequate, and $>70 \%$ as good (Bakarman, Kurashi \& Hanif, 1996).

\section{Statistical analysis}

Statistical analysis was performed using the Statistical Products and Service Solution (SPSS) version 25.0 (Inc.,
Chicago, IL, USA). Descriptive statistics were used to identify the average salt and sodium content as mean $\pm S D$ for each food category, the percentage of products that exceeded the criteria in IPC, and the scores for every domain and KAP as mean $\pm S D$ in percentages. One-way analysis of variance (ANOVA) test was used to compare the average sodium content between categories. Meanwhile, one-sample $t$-test was used to compare the average sodium content for each category to their own criteria. The average salt and sodium contents for each group was reported as mean $\pm S D$. The significance level for all analysis was set at $p<0.05$. In ensuring that assumptions of sample homogeneity were met, Levene's test was conducted prior to ANOVA and $t$-test, whereby $p>0.05$ indicated that the assumptions had not been violated.

\section{RESULTS}

\section{Salt and sodium content of fast food product categories}

A total of 105 food products consisting of 41 sandwich products, 11 chickenbased products, eight potato-based products, 15 dessert products, 13 salad products, six bread products, six sauce products, and five rice-based products were involved in the study of salt content in food products of fast food restaurants. Table 1 shows the average salt and sodium content per $100 \mathrm{~g}$ in the fast food product categories. Findings showed that sauce was the category that contained the highest salt content $(1.9 \pm 0.8 \mathrm{~g} / 100$ $\mathrm{g})$, followed by bread $(1.2 \pm 0.2 \mathrm{~g} / 100 \mathrm{~g})$, potato-based $(1.2 \pm 0.4 \mathrm{~g} / 100 \mathrm{~g})$, chickenbased $(1.2 \pm 0.3 \mathrm{~g} / 100 \mathrm{~g})$, sandwich $(1.1 \pm 0.6 \mathrm{~g} / 100 \mathrm{~g})$, rice-based $(0.7 \pm 0.3$ $\mathrm{g} / 100 \mathrm{~g})$, salad $(0.4 \pm 0.2 \mathrm{~g} / 100 \mathrm{~g})$, and dessert $(0.3 \pm 0.4 \mathrm{~g} / 100 \mathrm{~g})$. Using oneway ANOVA test, the salt and sodium contents for sauce product category were significantly $(p<0.05)$ higher compared 
to sandwich, dessert, salad, and ricebased product categories. Meanwhile, the salt and sodium contents for salad and dessert product categories were significantly $(p<0.05)$ lower compared to other categories.

\section{Percentage of fast food products that exceeded the sodium content in the International Product Criteria}

Of the 105 products involved, all potatobased products contained sodium content that exceeded the value stated by IPC. This was followed by bread products $(66.7 \%)$, rice-based products $(60.0 \%)$, sauce products $(50.0 \%)$, sandwich products $(36.6 \%)$, salad products $(30.8 \%)$, and dessert products $(6.7 \%)$; whereas none of the chicken-based products contained sodium content that exceeded the one stated in the IPC.

Table 2 shows the comparison of sodium content per $100 \mathrm{~g}$ for each category between the values stated in IPC and the findings from this study. Using one-sample $t$-test, results showed that the potato-based product category contained sodium content $(458.1 \pm 154.1$ $\mathrm{mg} / 100 \mathrm{~g})$ that significantly $(p<0.001)$ exceeded the value stated in IPC, which is $\leq 100 \mathrm{mg} / 100 \mathrm{~g}$. Meanwhile, chickenbased and dessert product categories contained sodium content $(456.4 \pm 130.6$ $\mathrm{mg} / 100 \mathrm{~g}$ and $101.3 \pm 148.0 \mathrm{mg} / 100$ g) that were significantly $(p<0.001)$ lower than the values stated in IPC (2016), which are $\leq 820 \mathrm{mg} / 100 \mathrm{~g}$ and $\leq 400 \mathrm{mg} / 100 \mathrm{~g}$. Moreover, the sodium content in bread and rice-based product categories also exceeded the values stated in IPC, although not significantly $(p=0.721$ and $p=0.616)$. On the other hand, the sodium content in sauce, sandwich, and salad product categories were lower than the values in IPC, although not significantly $(p=0.954$, $p=0.539$ and $p=0.321$ ).

\section{General characteristics of study population}

A total of 108 fast food consumers (76 females, 32 males) had participated in the salt intake awareness study. Most subjects $(75.0 \%)$ were aged between

Table 1. Salt and sodium content per $100 \mathrm{~g}$ in the fast food product categories (mean $\pm S D$ )

\begin{tabular}{lcc}
\hline $\begin{array}{l}\text { Fast food product } \\
\text { categories }\end{array}$ & $\begin{array}{c}\text { Salt content } \\
(\mathrm{g} / 100 \mathrm{~g})\end{array}$ & $\begin{array}{c}\text { Sodium content } \\
(\mathrm{mg} / 100 \mathrm{~g})\end{array}$ \\
\hline Sauce $(n=6)$ & $1.9 \pm 0.8^{\mathrm{a}}$ & $742.1 \pm 317.4^{\mathrm{a}}$ \\
Bread $(n=6)$ & $1.2 \pm 0.3^{\mathrm{b}}$ & $467.4 \pm 112.5^{\mathrm{b}}$ \\
Potato-based $(n=8)$ & $1.2 \pm 0.4^{\mathrm{c}}$ & $458.1 \pm 154.2^{\mathrm{c}}$ \\
Chicken-based $(n=11)$ & $1.2 \pm 0.3^{\mathrm{d}}$ & $456.4 \pm 130.6^{\mathrm{d}}$ \\
Sandwich $(n=41)$ & $1.1 \pm 0.6^{\mathrm{e}}$ & $425.7 \pm 251.3^{\mathrm{e}}$ \\
Rice-based $(n=5)$ & $0.7 \pm 0.3^{\mathrm{f}}$ & $265.7 \pm 105.8^{\mathrm{f}}$ \\
Salad $(n=13)$ & $0.4 \pm 0.2^{\mathrm{g}}$ & $149.3 \pm 72.2^{\mathrm{g}}$ \\
Dessert $(n=15)$ & $0.3 \pm 0.4^{\mathrm{h}}$ & $101.3 \pm 148.0^{\mathrm{h}}$ \\
\hline
\end{tabular}

Different letters $(\mathrm{a}-\mathrm{b}-\mathrm{c})$ indicate significant difference in salt and sodium content between categories determined by one-way ANOVA test

a - Sauce compared to sandwich, salad, dessert, rice-based

b - Bread compared to salad, dessert

c - Potato-based compared to salad, dessert

$\mathrm{d}$ - Chicken-based compared to salad, dessert

e - Sandwich compared to sauce, dessert

f - Rice-based compared to sauce

g - Salad compared to sauce, bread, potato-based, chicken-based, sandwich

$\mathrm{h}$ - Dessert compared to sauce, bread, potato-based, chicken-based, sandwich 
Table 2. Sodium content per $100 \mathrm{~g}$ for each fast food product categories between the values stated in IPC (2016) and the findings from this study (mean $\pm S D$ )

\begin{tabular}{lccc}
\hline \multirow{2}{*}{ Fast food product categories } & \multicolumn{2}{c}{ Sodium content $(\mathrm{mg} / 100 \mathrm{~g})$} & \\
\cline { 2 - 3 } & IPC & Amount & \\
\hline Sauce $(n=6)$ & $\leq 750$ & $742.1 \pm 317.4$ & 0.954 \\
Bread $(n=6)$ & $\leq 450$ & $467.4 \pm 112.5$ & 0.721 \\
Potato-based $(n=8)$ & $\leq 100$ & $458.1 \pm 154.2^{*}$ & $<0.001$ \\
Chicken-based $(n=11)$ & $\leq 820$ & $456.4 \pm 130.6^{*}$ & $<0.001$ \\
Sandwich $(n=41)$ & $\leq 450$ & $425.7 \pm 251.3$ & 0.539 \\
Rice-based $(n=5)$ & $\leq 240$ & $265.7 \pm 105.8$ & 0.616 \\
Salad $(n=13)$ & $\leq 170$ & $149.3 \pm 72.2$ & 0.321 \\
Dessert $(n=15)$ & $\leq 400$ & $101.3 \pm 148.0^{*}$ & $<0.001$ \\
\hline
\end{tabular}

Statistically significant at ${ }^{*} p<0.05$ determined by one-sample $t$-test

18-29 years, followed by 30-39 years (1.9\%), 40-49 years (3.7\%), and 50-59 years (19.4\%). Almost all subjects were Malay $(88.9 \%)$, followed by Chinese $(7.4 \%)$, Indian $(1.9 \%)$, and others $(1.9 \%)$. Majority of the subjects (78.7\%) were not married and $21.3 \%$ were married. Education level for most of the subjects $(60.2 \%)$ was degree, followed by
Foundation or Matriculation or Diploma or Certificate or Sijil Tinggi Pelajaran Malaysia (STPM) (24.1\%), 7.4\% with Sijil Pelajaran Malaysia (SPM), others (5.6\%), and Masters (2.8\%). Most of the subjects $(73.2 \%)$ did not have any monthly income or they earned less than RM1,000 a month; while $19.4 \%$ subjects earned at least RM3,000 a month, whereas $7.4 \%$

Table 3. Average score and distribution of subjects for every category level for knowledge (K), attitude $(\mathrm{A})$, practice $(\mathrm{P})$, and awareness (KAP) towards salt intake

\begin{tabular}{|c|c|c|c|}
\hline \multirow{2}{*}{ Category level } & \multirow{2}{*}{$\begin{array}{c}\text { Average score (\%) } \\
(\text { Mean } \pm S D)\end{array}$} & \multicolumn{2}{|c|}{ Total $(n=108)$} \\
\hline & & $n$ & $\%$ \\
\hline \multicolumn{4}{|l|}{ Knowledge (K) } \\
\hline Poor (<60\%) & $52.8 \pm 8.1$ & 44 & 40.7 \\
\hline Fair (60\%-70\%) & $64.6 \pm 2.1$ & 37 & 34.3 \\
\hline Good (>70\%) & $74.0 \pm 5.6$ & 27 & 25.0 \\
\hline \multicolumn{4}{|l|}{ Attitude (A) } \\
\hline Negative (<60\%) & $51.3 \pm 7.7$ & 11 & 10.2 \\
\hline Neutral (60\%-70\%) & $64.9 \pm 2.5$ & 20 & 18.5 \\
\hline Positive $(>70 \%)$ & $80.5 \pm 8.7$ & 77 & 71.3 \\
\hline \multicolumn{4}{|l|}{ Practice $(\mathrm{P})$} \\
\hline Inadequate (<60\%) & $48.1 \pm 5.9$ & 77 & 71.3 \\
\hline Adequate (60\%-70\%) & $65.2 \pm 3.6$ & 27 & 25.0 \\
\hline Good (>70\%) & $82.6 \pm 7.9$ & 4 & 3.7 \\
\hline \multicolumn{4}{|l|}{ Awareness (KAP) } \\
\hline Poor (<60\%) & $54.6 \pm 4.5$ & 29 & 26.9 \\
\hline Fair (60\%-70\%) & $63.6 \pm 3.4$ & 52 & 48.2 \\
\hline Good (>70\%) & $74.2 \pm 3.1$ & 27 & 25.0 \\
\hline
\end{tabular}


subjects earned between RM1,000RM2,999 a month.

\section{Consumers' level of knowledge, attitude, practice, and overall awareness (KAP) towards salt intake}

Table 3 shows the average score and number of subjects for every category level for knowledge, attitude, practice, and overall awareness towards salt intake. Most of the subjects (40.7\%) who participated had poor level of knowledge with an average score of $52.8 \pm 8.1 \%$. In contrast, $71.3 \%$ of the subjects had positive level of attitude with an average score of $80.5 \pm 8.7 \%$. However, most of the subjects $(71.3 \%)$ also had an inadequate level of practice with an average score of $48.1 \pm 5.9 \%$. For overall awareness (KAP), nearly half of the subjects (48.2\%) were at a fair level with an average score of $63.6 \pm 3.4 \%$. Meanwhile, $26.9 \%$ were at a poor level and only $25.0 \%$ were at a good level.

Table 4 shows the overall average score for knowledge, attitude and practice levels towards salt intake. Based on this table, fast food consumers involved in this study had a fair knowledge level of salt intake with an average score of $62.2 \pm 10.5 \%$, positive attitude level of salt intake $(74.6 \pm 12.6 \%)$, but an inadequate practice level of salt intake (53.6 $\pm 10.8 \%)$.

Table 4. Overall average score for knowledge $(\mathrm{K})$, attitude $(\mathrm{A})$ and practice $(\mathrm{P})$ levels towards salt intake $(n=108)$

\begin{tabular}{lc}
\hline Category & $\begin{array}{c}\text { Overall average } \\
\text { score }(\%) \\
(\text { Mean } \pm S D)\end{array}$ \\
\hline Salt intake & $62.2 \pm 10.5$ \\
knowledge & $74.6 \pm 12.6$ \\
Salt intake attitude & $53.6 \pm 10.8$ \\
Salt intake practice & \\
\hline
\end{tabular}

Table 5 shows the distribution of subjects according to answers for questions regarding KAP towards salt intake. A total of $32.4 \%$ subjects knew that the recommended amount of salt in a day is $5 \mathrm{~g}$. However, majority (43.5\%) of them did not know the recommended amount of salt in a day and $74.1 \%$ subjects thought they can consume a right amount of salt. More than half of the subjects (60.2\%) chose processed foods such as soy sauce, fast foods and snacks as the main sources of salt in the Malaysian diet. Only $37.0 \%$ subjects answered correctly on the relationship between salt and sodium. Almost all subjects (94.4\%) knew that a high salt diet could cause a serious health problem. Majority (63.0\%) responded that a high salt diet causes high blood pressure, but 25.9\% thought it could cause more than one health problem.

For attitude towards salt intake, only $53.7 \%$ subjects believed that identifying foods that have high amount of salt is very important and most of them $(59.3 \%)$ agreed that they try to minimise the amount of salt they consume. In addition to that, $51.9 \%$ of them thought that lowering the salt intake in their diet is important. However, only $45.4 \%$ of the subjects strongly agreed that their health would improve if they reduce their salt intake. Majority (51.9\%) of them also believed that adding salt to food would make the food tastier and 53.7\% subjects thought that it is important for them to check for salt content on food labels.

Most of the subjects (69.4\%) sometimes added sauce or soy sauce to their food. However, $72.2 \%$ of them claimed that they added the right amount of salt during preparation of food at home. In addition to that, most of them (71.3\%) also did not ask for less salt in the foods ordered when eating out. A total of $54.6 \%$ claimed that they consumed the right amount of salt and most of them $(52.8 \%)$ did not do anything on regular basis to control their salt intake, in which only $23.2 \%$ controlled the consumption of processed foods, 
Table 5. Distribution of subjects according to answers for questions regarding knowledge (K), attitude $(\mathrm{A})$ and practice $(\mathrm{P})$ towards salt intake

Questions

Answers

$\frac{\operatorname{Total}(n=108)}{n} \quad \%$

\section{Knowledge (K)}

Health professionals recommend that we should eat not more than a certain amount of salt each day. How much salt do you think that is?

5 g (about 1 teaspoon $)^{\dagger}$

$35 \quad 32.4$

$8 \mathrm{~g}$ (about 1 and a $1 / 2$ teaspoons)

$15 \quad 13.9$

$10 \mathrm{~g}$ (about 2 teaspoons)

$11 \quad 10.2$

Don't know

$47 \quad 43.5$

Which of the following do you think is the main source of salt in the Malaysian diet?

Salt added during cooking ${ }^{\ddagger}$

$31 \quad 28.7$

Salt from processed foods such as soy sauce, fast foods and snacks

$65 \quad 60.2$

Salt from natural food sources such as shellfish and milk

$\begin{array}{ll}6 & 5.6 \\ 6 & 5.6\end{array}$

How much salt do you think you can consume?

Very little

$13 \quad 12.0$

Right amount

$80 \quad 74.1$

Too much

7

Don't know

$8 \quad 7.4$

Information on the amount of

Salt contains sodium ${ }^{+}$

$40 \quad 37.0$

salt within a food product in Malaysia is usually displayed on the food label. What is the relationship between salt and sodium?

Do you think that a high salt diet could cause a serious health problem?

Salt and sodium are the same

$32 \quad 29.6$

Sodium contains salt

$5 \quad 4.6$

Don't know

$31 \quad 28.7$

$\mathrm{Yes}^{\dagger}$

$102 \quad 94.4$

No

$\begin{array}{ll}4 & 3.7\end{array}$

Don't know

$2 \quad 1.9$

If you answer Yes in question 5 above, what are the health problems? (Subjects can choose more than one answer)

High blood pressure ${ }^{+}$

$68 \quad 63.0$

Osteoporosis ${ }^{\dagger}$

$0 \quad 0.0$

Stomach cancer ${ }^{+}$

$\begin{array}{ll}0 & 0.0\end{array}$

Kidney stones ${ }^{\dagger}$

$\begin{array}{ll}1 & 0.9\end{array}$

None of the above

$8 \quad 7.4$

Don't know

$3 \quad 2.8$

More than one health problem ${ }^{+}$

$28 \quad 25.9$


Table 5. Distribution of subjects according to answers for questions regarding knowledge (K), attitude $(\mathrm{A})$ and practice $(\mathrm{P})$ towards salt intake (continued)

\begin{tabular}{|c|c|c|c|}
\hline \multirow{2}{*}{ Questions } & \multirow{2}{*}{ Answers } & \multicolumn{2}{|c|}{ Total $(n=108)$} \\
\hline & & $n$ & $\%$ \\
\hline \multicolumn{4}{|l|}{ Attitude (A) } \\
\hline \multirow{4}{*}{$\begin{array}{l}\text { How important is it for you } \\
\text { to identify food that has high } \\
\text { amount of salt? }\end{array}$} & Very important ${ }^{\ddagger}$ & 38 & 35.2 \\
\hline & Important & 58 & 53.7 \\
\hline & Less important & 9 & 8.3 \\
\hline & Not important & 3 & 2.8 \\
\hline \multirow{4}{*}{$\begin{array}{l}\text { I try to minimise the amount of } \\
\text { salt that I consume. }\end{array}$} & Strongly agree & 26 & 24.1 \\
\hline & Agree & 64 & 59.3 \\
\hline & Slightly agree & 16 & 14.8 \\
\hline & Disagree & 2 & 1.9 \\
\hline \multirow{4}{*}{$\begin{array}{l}\text { How important for you in } \\
\text { lowering the salt intake in your } \\
\text { diet? }\end{array}$} & Very important $t^{\ddagger}$ & 42 & 38.9 \\
\hline & Important & 56 & 51.9 \\
\hline & Less important & 8 & 7.4 \\
\hline & Not important & 2 & 1.9 \\
\hline \multirow{4}{*}{$\begin{array}{l}\text { My health would improve if I } \\
\text { reduce the salt intake in my diet. }\end{array}$} & Strongly agree ${ }^{\ddagger}$ & 49 & 45.4 \\
\hline & Agree & 49 & 45.4 \\
\hline & Slightly agree & 9 & 8.3 \\
\hline & Disagree & 1 & 0.9 \\
\hline \multirow{4}{*}{$\begin{array}{l}\text { I believe that by adding salt to } \\
\text { food would make the food tastier. }\end{array}$} & Strongly agree & 19 & 17.6 \\
\hline & Agree & 56 & 51.9 \\
\hline & Slightly agree & 25 & 23.2 \\
\hline & Disagree $^{\ddagger}$ & 8 & 7.4 \\
\hline \multirow{4}{*}{$\begin{array}{l}\text { How important is it for you to } \\
\text { check for salt content on food } \\
\text { labels? }\end{array}$} & Very important $t^{\ddagger}$ & 24 & 22.2 \\
\hline & Important & 58 & 53.7 \\
\hline & Less important & 23 & 21.3 \\
\hline & Not important & 3 & 2.8 \\
\hline
\end{tabular}


Table 5. Distribution of subjects according to answers for questions regarding knowledge (K), attitude $(\mathrm{A})$ and practice $(\mathrm{P})$ towards salt intake (continued)

\begin{tabular}{|c|c|c|c|}
\hline \multirow{2}{*}{ Questions } & \multirow{2}{*}{ Answers } & \multicolumn{2}{|c|}{ Total $(n=108)$} \\
\hline & & $n$ & $\%$ \\
\hline \multicolumn{4}{|l|}{ Practice (P) } \\
\hline \multirow{4}{*}{$\begin{array}{l}\text { During each meal time, do you } \\
\text { add sauce or soy sauce to the } \\
\text { food? }\end{array}$} & Never ${ }^{\ddagger}$ & 15 & 13.9 \\
\hline & Sometimes & 75 & 69.4 \\
\hline & Often & 14 & 13.0 \\
\hline & Always & 4 & 3.7 \\
\hline \multirow{4}{*}{$\begin{array}{l}\text { How much salt is added during } \\
\text { preparation of food at home? }\end{array}$} & None & 1 & 0.9 \\
\hline & Very little & 28 & 25.9 \\
\hline & Right amount & 78 & 72.2 \\
\hline & Too much & 1 & 0.9 \\
\hline \multirow{4}{*}{$\begin{array}{l}\text { Do you ask for less salt in the } \\
\text { food that you ordered when } \\
\text { eating out? }\end{array}$} & Never & 77 & 71.3 \\
\hline & Sometimes & 30 & 27.8 \\
\hline & Often & 1 & 0.9 \\
\hline & Always ${ }^{\ddagger}$ & 0 & 0.0 \\
\hline \multirow{4}{*}{$\begin{array}{l}\text { How much salt do you think you } \\
\text { consume? }\end{array}$} & Very little & 13 & 12.0 \\
\hline & Right amount & 59 & 54.6 \\
\hline & Too much & 24 & 22.2 \\
\hline & Don't know & 12 & 11.1 \\
\hline \multirow{3}{*}{$\begin{array}{l}\text { Do you do anything on regular } \\
\text { basis to control your salt intake? }\end{array}$} & Yes $^{\ddagger}$ & 45 & 41.7 \\
\hline & No & 57 & 52.8 \\
\hline & Don't know & 6 & 5.6 \\
\hline \multirow{7}{*}{$\begin{array}{l}\text { If you answer Yes in question } 11 \text {, } \\
\text { what do you do? (Subjects can } \\
\text { choose more than one answer) }\end{array}$} & $\begin{array}{l}\text { Avoid/minimise the consumption of } \\
\text { processed foods }{ }^{\dagger}\end{array}$ & 25 & 23.2 \\
\hline & $\begin{array}{l}\text { Read the salt content on the food } \\
\text { labels }^{+}\end{array}$ & 0 & 0.0 \\
\hline & Buy alternative foods with low salt ${ }^{+}$ & 7 & 6.5 \\
\hline & Not adding salt when cooking ${ }^{+}$ & 1 & 0.9 \\
\hline & More than one routine action ${ }^{+}$ & 10 & 9.3 \\
\hline & All of the above ${ }^{+}$ & 2 & 1.9 \\
\hline & None & 63 & 58.3 \\
\hline
\end{tabular}

${ }^{\dagger}$ Correct answer

${ }^{\ddagger}$ Best answer 
$6.5 \%$ bought alternative foods with low salt, and $0.9 \%$ did not add salt when cooking. Only $9.3 \%$ of them did more than one of these actions routinely. On the other hand, majority of them $(58.3 \%)$ did none of these actions.

\section{DISCUSSION}

In the first phase of this study, salt content in food products of fast food restaurants were identified and assessed. The results showed that in general, sauce was the category that contained the highest salt content $(1.9 \mathrm{~g} / 100 \mathrm{~g})$ compared to the other categories and were significantly $(p<0.05)$ higher compared to sandwich, dessert, salad, and rice-based product categories. This result is consistent with a previous study by Heredia-Blonval et al. (2014), which reported that the highest salt content was found in the sauce category $(2.2 \mathrm{~g} / 100 \mathrm{~g})$ compared to other food categories of fast food restaurants. According to MDG (NCCFN, 2021), sauces are one of the high salt sources. Additionally, this study also found that salad category was one of the categories that contained the lowest amount of salt compared to other categories besides dessert. Heredia-Blonval et al. (2014) in their study also reported that salad category contained the lowest amount of salt compared to other categories.

In comparison with the sodium content stated in the IPC, $50.0 \%$ of the products under the sauce product category exceeded the criteria value suggested by IPC. Although the average sodium content in the sauce product category $(742.1 \mathrm{mg} / 100 \mathrm{~g})$ was not significantly $(p=0.954)$ higher than the criteria in IPC, it is still worrying considering that sauces are not often eaten just as they are. Instead, sauces are often eaten with other foods such as fast food (Codex Alimentarius, 1995), which is also a high salt source (NCCFN, 2021). This study also found that all potato-based products contained sodium content $(458.1 \mathrm{mg} / 100 \mathrm{~g})$ that significantly $(p<0.001)$ exceeded the value stated by IPC.

In the second phase of this study, KAP towards salt intake among fast food consumers was assessed. Overall, majority of the consumers who participated in this study were reported to have a fair level of salt intake awareness $(63.6 \%)$.

The results showed that in general, consumers had a fair knowledge level (62.2\%). However, two in five consumers had poor level of knowledge. Additionally, three quarters of subjects claimed that they can consume a right amount of salt despite only a third of them who actually knew the correct recommended amount of salt in a day, which is $5 \mathrm{~g}$ (WHO, 2012). Moreover, $43.5 \%$ of them were not knowledgeable about this recommended level. This finding is in line with a study by Grimes et al. (2017), in which most of their subjects did not know the recommended amount of salt in a day. More than half of the subjects in this current study $(60.2 \%)$ were knowledgeable about the sources of salt in the Malaysian diet, which are processed foods such as soy sauce, fast foods and snacks (NCCFN, 2021). This study also found that only $37.0 \%$ subjects were informed on the relationship between salt and sodium, in which salt contains sodium. This differed from a study by Nasreddine et al. (2014) where a majority of their subjects knew about the correct relationship between salt and sodium. Other than that, almost all subjects (94.4\%) knew that a high salt diet could cause a serious health problem, with majority of them (63.0\%) thinking that a high salt diet could cause hypertension alone. However, only $25.9 \%$ of them knew that it could pose more than one health problems including hypertension, osteoporosis, stomach 
cancer, and kidney stones. This finding is in line with studies by IPH (2016) and Aparna et al. (2019), in which most of the subjects in these studies were not aware of the relationship between a high salt diet and other diseases, aside from hypertension.

For attitude towards salt intake, the consumers were generally at a positive level $(74.6 \%)$. This is expected as majority of them $(71.3 \%)$ had a positive level with an average score of $80.5 \%$. Most of them $(53.7 \%)$ knew that identifying foods that have high amount of salt is important and $59.3 \%$ of them claimed that they try to minimise their consumption of salt. Additionally, $51.9 \%$ of them knew that lowering the salt intake in their diet is important. This finding is similar to a study by Aparna et al. (2019) that was conducted in North India. The current study also found that $45.4 \%$ of subjects agreed and strongly agreed that their health would improve if they reduce their salt intake in their diet, which is also in line with a study by Grimes et al. (2017) that was conducted among Australians. Besides that, $51.9 \%$ of the subjects claimed that adding salt to food would make the food tastier and 53.7\% claimed that it is important to check for salt content on food labels.

In contrast to the fair level of knowledge and positive level of attitude towards salt intake, the consumers in general had an inadequate level (53.6\%) of practice towards salt intake, as majority of them $(71.3 \%)$ were scored at an inadequate level (48.1\%). According to Mat Daud et al. (2018), being equipped with the knowledge of nutrition often probes a person to practise healthy eating habits. In accordance to that, Spronk et al. (2014) also reported that having higher knowledge of nutrition was associated with better or healthier food consumption. In this study, $72.2 \%$ of the consumers claimed to practise adding salt in a right amount during the preparation of foods at home and $54.6 \%$ claimed that they practise consuming salt in a right amount. However, majority of the consumers did not know the recommended amount of salt in a day. This showed that even if the consumers had good knowledge of food and nutrition, it does not ensure good practices of salt intake. According to Banwat et al. (2012), the good practices of healthy eating cannot be ensured solely based on nutrition knowledge alone.

According to Shaziman et al. (2017), the attitude towards healthy eating influences a person's dietary habits. However, most of the findings in this study showed otherwise. Firstly, this study reported that $69.4 \%$ of consumers sometimes added sauce or soy sauce to their food. According to Shahar et al. (2019), Malaysians still consume high amount of salt through sauces even if they do not add salt to their food. As mentioned previously, sauces contain the highest amount of salt compared to other fast food categories (HerediaBlonval et al., 2014) and are often eaten with other meals (Codex Alimentarius, 1995). This practice has contradicted majority of the consumers' attitude in this study, which reported that identifying foods that have high amount of salt is important. In addition to that, $71.3 \%$ of the consumers never asked for less salt in the foods ordered when eating out despite majority of them claiming that they try to minimise their salt consumption and that lowering their salt consumption is important. In light of this, it is worth mentioning that while fast food restaurants serve ready-to-eat dishes compared to other forms of food, request on lowering salt in fast foods at the point of re/heating the food can be made. For example, consumers could ask for less salt to be sprinkled on their French fries during order. Only 41.7\% of the consumers controlled their salt intake on a regular basis, and $58.3 \%$ 
consumers claimed to do none of the salt intake practices such as controlling their consumption of processed foods, buying alternative foods with low salt or not adding salt when cooking. Aside from that, $58.3 \%$ of them also did not read the salt content on food labels although most of the consumers claimed that checking for salt content on food labels is important.

Phase two of this study showed that although the knowledge and attitude of the consumers towards salt intake were good, their practice proved otherwise. Similar findings were also reported on a study of KAP towards healthy eating among university students in Selangor (Hassan et al., 2015). The limitations in this current study were that the types of food products involved were limited and did not cover other categories of fast foods such as pizza. Additionally, the number of restaurants chosen were also limited. Hence, the findings cannot be generalised to represent all fast food products from all fast food restaurants. In regards to the study on KAP, the questionnaires were distributed online instead of physically approaching the samples. This method of administering the questionnaire might have posed bias in this age group of samples, whereby the questionnaire might have reached more of the younger age groups who are internet savvy compared to the older age groups. For future study, more food products covering all fast food categories from more restaurants should be considered. In addition, future KAP study should also involve approximately equal number of subjects from every age group to minimise bias.

\section{CONCLUSION}

Among the fast food categories, sauce product category had the highest amount of salt. Additionally, potato-based product category contained sodium content that significantly $(p<0.05)$ exceeded the criteria in IPC. As for the KAP study, fast food consumers generally had fair level of overall awareness, fair level of knowledge and positive attitude towards salt intake. Still, they did not practise it in their daily lives. Therefore, more strategic interventions that will enable the control of salt intake among adults in Malaysia are needed.

\section{Acknowledgement}

The authors would like to acknowledge Subway ${ }^{\circledR}$ and Texas Chicken for granting us permission to conduct the research. We are most thankful to all subjects who have participated in this study. We would also like to acknowledge the Faculty of Health Sciences, Universiti Kebangsaan Malaysia for support.

\section{Authors' contributions}

ZNZA, led the data collection, data analysis and interpretation, and prepared the manuscript; NZMS, assisted in the statistical analysis; $\mathrm{HH}$, principal investigator, conceptualised and designed the study and reviewed the manuscript.

\section{Conflict of interest}

There was no conflict of interest involved.

\section{References}

Ambak R, Pei Sien Y, Ahmad N, Fadhli Mohd Yusof M, Aris T, Mustapha F, Zainuddin AA, Abdul Ghaffar S, Baharuddin A, Michael V, Ariffin Omar Z, Sulong R \& Mustafa M (2014). Sodium intake among normotensive health staff assessed by 24-hour urinary excretion: A cross-sectional study. Mal J Nutr 20(3):317326.

Aparna P, Salve H, Anand K, Ramakrishnan L, Gupta S \& Nongkynrih B (2019). Knowledge and behaviors related to dietary salt and sources of dietary sodium in north India. $J$ Family Med Prim Care 8(3):846-852.

Bakarman MA, Kurashi NY \& Hanif M (1996). Utilization of laboratory investigations: study of knowledge, attitude and practice among primary care physicians. J Fam Community Med 3(2):32-40.

Banwat ME, Lar LA, Daboer J, Audu S \& Lassa S (2012). Knowledge and intake of fruit and vegetables consumption among adults in an urban community in north central Nigeria. Niger Health J 12(1):12-15. 
Choices International Foundation (2016). International Product Criteria. From https:// www.choicesprogramme.org/uploads/PDF / choices-internationalcriteria-2015-totalsugar-2018-def.pdf [Retrieved March 1 2019].

Cochran WG (1977). Sampling Techniques. 3rd Ed. John Wiley \& Sons, New York.

Codex Alimentarius (1995). Codex general standard for food additives. Codex Stan 192-1995.

Dewan Bahasa dan Pustaka (2010). Kamus Dewan Edisi Keempat. Dewan Bahasa dan Pustaka, Kuala Lumpur.

Dunford E, Webster J, Woodward M, Czernichow S, Yuan YL, Jenner K, Mhurchu CN, Jacobson M, Campbell N \& Neal B (2012). The variability of reported salt levels in fast foods across six countries: Opportunities for salt reduction. CMAJ 184(9):1023.

Grimes CA, Kelley SJ, Stanley S, Bolam B, Webster J, Khokhar D \& Nowson CA (2017). Knowledge, attitudes and behaviours related to dietary salt among adults in the state of Victoria, Australia 2015. BMC Public Health 17(1):532-532.

Hassan M, Ghazi H, Umar NS, Masri N, Mohd Jamil S, Md Isa Z \& Safian N (2015). Knowledge, attitude and practice of healthy eating and associated factors among University Students in Selangor, Malaysia. Pak J Nutr 14(12):892897.

Heredia-Blonval K, Blanco-Metzler A, MonteroCampos M \& Dunford E (2014). The salt content of products from popular fast-food chains in Costa Rica. Appetite 83:173-177.

IPH (2014). National Health and Morbidity Survey 2014: Malaysian Adult Nutrition Survey (MANS) Vol. I: Methodology and General Findings. Institute for Public Health, Ministry of Health Malaysia, Kuala Lumpur.

IPH (2015). National Health and Morbidity Survey 2015 (NHMS 2015). Vol. II: Non-Communicable Diseases, Risk Factors and Other Health Problems. Institute for Public Health, Ministry of Health Malaysia, Kuala Lumpur

IPH (2016). Determination of Dietary Sodium Intake Among the Ministry of Health Staff 2015 (MySalt 2015). Institute for Public Health, Ministry of Health Malaysia, Kuala Lumpur.

IPH (2017). Malaysian Burden of Disease and Injury Study 2009- 2014. Institute for Public Health, Ministry of Health Malaysia, Kuala Lumpur.
Mat Daud N, Fadzil NI, Yan LK, Makbul IAA, Yahya NFS, Teh AH \& Abdul Rahman H (2018). Knowledge, attitude and practice regarding dietary fibre intake among Malaysian rural and urban adolescents. Mal J Nutr 24:77-88.

$\mathrm{MOH}$ (2016). National Strategic Plan for NonCommunicable Disease (NSP-NCD) 2016-2025. Seksyen NCD, Putrajaya.

Mozaffarian D, Fahimi S, Singh G, Micha R, Khatibzadeh S, Engell R, Lim S, Danaei G, Ezzati M \& Powles J (2014). Global sodium consumption and death from cardiovascular causes. N Engl J Med 371(7):624-634.

Nasreddine L, Akl C, Al-Shaar L, Almedawar MM $\&$ Isma'eel H (2014). Consumer knowledge, attitudes and salt-related behaviour in the Middle-East: The case of Lebanon. Nutrients 6(11):5079-5102.

NCCFN (2021). Malaysian Dietary Guidelines 2020. Technical Working Group on Nutritional Guidelines, National Coordinating Committee on Food and Nutrition. Ministry of Health Malaysia, Putrajaya.

O’Donnell SI, Hoerr SL, Mendoza JA \& Tsuei Goh E (2018). Nutrient quality of fast food kids meals. Am J Clin Nutr 88(5): 1388-1395.

Pallant J (2005). SPSS Survival Manual: A Step by Step Guide to Data Analysis Using SPSS For Windows (2nd edn). Sabon By Bookhouse, Sydney, NSW.

Shahar S, You Y, Zainuddin N, Michael V, Ambak R, Haron H, He F \& Macgregor G. (2019). Sodium content in sauces - a major contributor of sodium intake in Malaysia: A cross-sectional survey. BMJ Open 9:e025068. doi:10.1136/ bmjopen-2018-025068.

Shaziman S, Rani MDM, Nor Aripin KN, Hamid NA, Sulaiman WNW, Rahman ZA \& Abdullah MY (2017). Research article assessing nutritional knowledge, attitudes and practices and body mass index of adolescent residents of orphanage institutions in Selangor and Malacca. Pak J Nutr 16(6):406-411.

Spronk I, Kullen C, Burdon C \& O'Connor H (2014). Relationship between nutrition knowledge and dietary intake. Br J Nutr 111(10):1713-1726.

WHO (2012). Guideline: Sodium Intake for Adults and Children. World Health Organization From https://www.who.int/nutrition/publications / guidelines/sodium_intake_printversion.pdf [Retrieved February 22 2019]. 